\title{
Green Synthesis of Silver nanoparticles and its effect on the growth of Zea mays $L$.
}

\author{
Sriram Thiruvengadam ${ }^{1 *}$, Mareeswari Ganesan $^{2}$ Pandidurai Vanniappan ${ }^{3}$ \\ 1AssistantProfessor, Department of Life Sciences, KristuJayanti College, Bangalore, Karnataka, India. \\ 2 Assistant Professor, Department of Biotechnology, Sri Kaliswari College, Sivakasi,Tamil Nadu, India. \\ 3 Assistant Professor, Department of Botany, Government Arts College, Melur, Tamil Nadu, India. \\ ${ }^{*}$ Corresponding Author: ramidster@Gmail.com
}

\begin{abstract}
In the present study, an attempt was made to analyze the growth of Zea mays L. supplemented with Silver nanoparticles in different concentration (20ppm, 40ppm and 60ppm).Silver nanoparticles was synthesized from leaf extract of Zea mays L. The synthesized nanoparticle was characterized and confirmed using UV-Vis spectrometric analysis, SEM, and FTIR analysis. Synthesis of Silver nanoparticle was confirmed by colour change and the peak at $500 \mathrm{~nm}$ using UV Visible spectrophotometer. Seed germination and In vivo growth analysis of Zea mays $\mathrm{L}$. supplemented with silver nanoparticles exhibited maximum growth at 60 ppm concentration. Accumulation of silver nanoparticle in the plant was measured using atomic absorption spectroscopy.
\end{abstract}

\section{Introduction}

Nanotechnology is a science with its new tools, systems and materials that has revolutionized agriculture. Indeed it has a significant effect in agricultural sector with modernization of novel cultivars, intelligent system for processing food and degradation/removal of herbicides from soil and plants (1)

In the late 1990's Nano-Era started worldwide with support and investments of the government. National Nanotechnology Institute of United States has contributed in the development of nano-research in the beginning of 2000. After which a number of metal and carbon based nanomaterials are produced and used in various fields and applications (2). The eco-friendliness, cost effectiveness of plant mediated synthesis of nanoparticles makes it very popular comparing to other methods of nanoparticle synthesis. They have size between 1-100 $\mathrm{nm}$ with superior chemical, physical unique and novel properties which can be readily synthesized. The most studied metallic nanoparticles are Gold, Silver, Copper which have broad applications including its use as detector, surface coating agents, antimicrobials etc. (3) As Secondary metabolites are present in plants nanoparticles synthesized from them have special attention with its unique biological applications. Plant mediated nanoparticle synthesis is more advantageous as they are less toxic with nanoparticles synthesized by chemical or physical methods. Moreover plants are readily available with different types of secondary metabolites like terpenoids, flavonoids, alkalodis and ketones which are good reducing/stalizing agent in synthesis of metal nanoparticles.(4)

Green chemistry is considered as an alter in using environmentally toxic process, products with serious consequences when they are used in agriculture, medicine, industries etc. It is also suggested that green chemistry approach might save a huge amount of money by the end of 2020. When green chemistry combines with nanobiotechnology in developing products that benefit mankind, industries and environment it is broad and huge. Countries which have rich biodiversity need to convert its resources in to methods, compound and tools that gives sustainable growth. In June 2009 applications of nanoparticles in agriculture and food were proclaimed by Food and Agricultural Organization (FAO) that includes nano sized biofortification, wide ranging fields, nanocoating and Nano filtration. Nanaoparticles are also called as magic bullets as they have nutrients or substances that enhance the productivity of plants. (5)

Green synthesized nanoparticles are used commonly as nano-pesticides, nanofertilzers and even as herbicides that helps the plant's productivity with avoiding the excessive use of chemical fertilizers. Nanoparticles regulate the development of plants and increase their metabolic process. They can have either positive or negative influence on the plant growth. This depends on the concentration of nanoparticles. Hence it is essential to examine carefully with the concentration of nanaoparticles and its interaction with plant that is helpful in the future prospective of Plant sciences. (6)

Silver nanoparticles exhibits great promise in agricultural applications especially in enhancing the rate and growth of diploid and triploid seeds. Capping of phytochemicals in green synthesis of nanoparticles have benign effect in agriculture. They can enhance the growth, crop yield and germination of seed without altering the natural attributes in plant. (7)

Roman et al., in their study proposed that silver nanoparticles at low concentrations has an beneficial effect in seedling development of green beans. They found that the highest silver nanoparticle concentration was not effective with seeds as it distrupted the symbiotic relationship with Rhizobia. They concluded that even though silver nanoparticles have promising results in growth of beans the interactions of plants with soil microorganisms has negative economic impact 
(8). MervatShSadak in his study used foliar application of silver nanoparticles with different concentration (20, 40 and $60 \mathrm{mg} / \mathrm{l}$ ) in fenugreek plant. Improvement in growth parameters including shoot length, number of leaves/plant, shoot weight and chlorophyll content in his study. He also concluded with various concentrations applied $40 \mathrm{mg} / \mathrm{l}$ silver nanoparticles was the optimum concentration for the growth and improvement of fenugreek (9) Application of nanoparticle in plant thereby promoting its growth is a contemporary approach in the field of agriculture. Indeed it is a novel and promising approach in protecting the plant under stress (10).

\section{Materials and Methods:}

\section{Sample collection:}

Maize leaves were collected from Tamilnadu Agricultural University, Madurai. The collected leaves were washed with double distilled water and air dried. Then it was cut into small pieces and homogenized with the help of mortar and pestle and dispensed in $100 \mathrm{ml}$ of distilled water and heated for 5 minutes at $70-80^{\circ} \mathrm{C}$. The extract was then filtered using Whatman's No.1 filter paper. The filtrate was collected in a clean and dried conical flask by standard sterilized filtration method and was stored at $30^{\circ} \mathrm{C}$.

\section{Synthesis of silver nanoparticles using maize leaves}

\section{Preparation of $1.0 \mathrm{~m}$ M silver nitrate:}

$0.008 \mathrm{~g}$ of silver nitrate was dissolved in $50 \mathrm{ml}$ of sterile distilled water in a sterile conical flask .It was freshly prepared for every time use.

\section{Synthesis of silver Nanoparticles:}

The synthesis of silver nanoparticles was prepared by mixing $5.0 \mathrm{ml}$ of Zea mays L. leaf extract with $50 \mathrm{ml}$ of freshly prepared $1 \mathrm{mM}$ aqueous silver nitrate solution. The color change was observed in the resultant solution.

\section{Purification of silver nanoparticle synthesized from the leaf extract of Zea mays L.:}

Centrifugation at $10,000 \mathrm{rpm}$ for 10 minutes was done after color change. The pellets were air dried and supernatant was discarded. The content was mixed with equal volume of distilled water. Centrifugation was repeated several times to attain better separation.

Characterization of synthesized silver nanoparticles:

\section{UV-Visible spectra analysis:}

UV-Visible spectrophotometer was used for monitoring the reduction of silver to nanoparticles. The sample was mixed with distilled water and UV-Visible spectral analysis was done between the range of 340$600 \mathrm{~nm}$. The analysis was done in every 1,3.6,12 and 24 hours).

\section{Scanning Electron Microscope (SEM):}

The dimensions of the synthesized silver nanoparticles that includes shape, size surface are analyzed using SEM. For this analysis the sample containing silver nanoparticles was sonicated at room temperature for 15 minutes. Then a small drop of the sample was placed on glass slide and air dried which was then observed under SEM.

\section{Energy dispersive X-ray spectrometer (EDAX):}

This technique uses a multi channel analyzer which is used for counting the pulses. The elemental composition is measured more reliably using EDAX.

\section{FTIR (Fourier TranformInfraRed Spectroscopy):}

The functional groups of a sample are more significantly identified using the tool FTIR. This tool is also useful in identifying the chemical bonds of a molecule.

\section{Seed germination analysis}

Seeds of Zea mays L. were obtained from Tamil Nadu agricultural College, Madurai. Seed germination study was carried out in a petridish placed with a water porous filter paper. To each $5 \mathrm{ml}$ of silver nanoparticles with various concentration (20ppm, 40ppm and 60ppm) was added. The seeds were incubated in dark and germination was monitored during $6^{\text {th }}$ and $12^{\text {th }}$ day. The following parameters were used to monitor the germination of seeds.

In vivo growth analysis of Zea mays $L$.

\section{Preparation of the experimental soil}

The experimental soil for raising the cultivars was sandy loam. The soil was sterilized by solar sterilization method for 5 days. It was then analyzed for its physico chemical properties.

The analyzed soil was taken in earthen pots of size $30 \times 33 \mathrm{~cm}$ and filled in for about two-third of their height (5 kg of soil per pot).

In vivo growth of Zea mays L. supplemented with nanoparticles by foliar spray was carried out by two different methods

1. Different concentration of nanoparticles (20 ppm, 40 ppm and 60 ppm) supplemented at one time.

2. Different concentration of nanoparticles (20 ppm, 40 ppm and 60 ppm) supplemented continuosly for 15 days.

On $15^{\text {th }}$ day the following parameters were analyzed for the growth of Zea mays L. using nanoparticles.

\section{Estimation of protein}

The total soluble protein was estimated by Lowry's method (Lowry et. al., 1951). Fresh leaf samples were ground in $10 \mathrm{~mL}$ of distilled water using mortar and pestle. The homogenate was spun at $3000 \mathrm{rpm}$ for 5 
minutes. The supernatant was taken and the pellet was discarded. To the supernatant, $1 \mathrm{~mL}$ of ice-cold $10 \%$ $(\mathrm{w} / \mathrm{v})$ trichloroacetic acid was added and kept in ice for 10 minutes. The extract was centrifuged at $5000 \mathrm{rpm}$ for 10 minutes. The pellet was dissolved in $0.1 \mathrm{~N} \mathrm{NaOH}$ and used as the test solution.

\section{Reagents for protein estimation}
A) $\mathrm{CuSO}_{4}: 0.5 \%$ - Solution A
B) Sodium-Potassium tartarate: 1\% - Solution B
C) $\mathrm{Na}_{2} \mathrm{CO}_{3}$ solution in $0.1 \mathrm{~N} \mathrm{NaOH}: 2 \%$ - Solution C

The mixture of $0.5 \mathrm{~mL}$ of $A$ and $0.5 \mathrm{~mL}$ of $B$ with 4.9 $\mathrm{mL}$ of solution $\mathrm{C}$ is known as alkaline copper reagent. An aliquot of $0.1 \mathrm{~mL}$ of test solution was taken in a test tube and $0.4 \mathrm{~mL}$ of distilled water, $0.5 \mathrm{~mL}$ of freshly diluted (1:1) folin phenol reagent and $5.5 \mathrm{~mL}$ of alkaline copper reagent were added. Contents in the tube were mixed immediately and left undisturbed for 10 minutes for the development of blue colour. The absorbance was measured at $650 \mathrm{~nm}$ with a Systronics model 106 spectrophotometer with alkaline copper reagent as blank. The protein content was calculated from a standard graph of protein constructed with bovine serum albumin (BSA) as marker protein.

\section{Estimation of free amino acids}

Free amino acids were estimated by ninhydrin assay (Jayaraman, 1981) method. The leaf material (200 $\mathrm{mg}$ ) was ground in $10 \mathrm{~mL}$ of ethanol. The homogenate was centrifuged at $5000 \mathrm{rpm}$ for 3 minutes. The pellet was discarded and the supernatant was used as the test solution. To $1 \mathrm{~mL}$ of the test solution, $3 \mathrm{~mL}$ of distilled water and $1 \mathrm{~mL}$ of ninhydrin reagent were added and mixed thoroughly. After mixing, the test tube was kept in boiling water bath for 10 minutes. Then the tube was cooled down to room temperature and $1 \mathrm{~mL}$ of $50 \%$ ethanol was added. The absorbance was measured at $550 \mathrm{~nm}$.

\section{Estimation of proline}

By homogenizing $0.5 \mathrm{~g}$ of plant material in $10 \mathrm{ml}$ of $3 \%$ aqueous sulphosalicyclic acid the extract was prepared. Then the homogenate was filtered through Whatman No. 2 filter paper. $2.0 \mathrm{ml}$ of filtrate was taken in a test tube and $2.0 \mathrm{ml}$ of glacial acetic acid and $2 \mathrm{ml}$ of ninhydrin were added. The mixture was heated in boiling water bath for 1 hour. $4 \mathrm{ml}$ of toluene was added to the reaction mixture and the red color intensity is measured at $520 \mathrm{~nm}$.

\section{Analysis of silver nanoparticles in plant material}

The nanoparticles accumulated in experimental plants were assayed after 15 days. Silver concentration in plants were analyzed using the method of Baker et al. (1994). The plant sample as a whole was washed, dried in oven at $160^{\circ} \mathrm{C}$ for 40 minutes and digested in a mixture of nitric acid and perchloric acid (10:1). Then the solution was centrifuged at $5000 \mathrm{rpm}$ for 5 minutes and double filtered with whatmann filter paper no.4 and the filtrate was used for analyzing $\mathrm{Ni}$ concentration by Atomic Absorption Spectrometry (Shimadzu Model AA 6300), available in the Science Instrumentation Centre of AyyaNadar Janaki Ammal College (Autonomous), Sivakasi, Tamil Nadu.

Table 1 Parameters used for seed germination analysis

\begin{tabular}{|l|l|}
\hline S.No & Parameter used \\
\hline 1 & Root length \\
\hline 2 & Shoot length \\
\hline 3 & Fresh weight(12 ${ }^{\text {th }}$ day $)$ \\
\hline 4 & Dry weight(12 ${ }^{\text {th }}$ day $)$ \\
\hline
\end{tabular}

\section{Accumulation Factor (AF)}

The Accumulation Factor (AF) was considered to determine the quantity of nanoparticles absorbed by the plant from soil. This is an index of the plant to accumulate a particular nanopartilce with respect to its concentration in the soil and is calculated using the formula (Ghosh and Singh, 2005; Yoon et al., 2006):

\section{Accumulation Factor (AF)}

$=$ Nanoparticle concentration in the tissue of the whole plant

\section{Intial concentration of metal in the substrate.}

\section{Statistical analysis}

Each experiment was repeated three times and each treatment had 10 replicates. All data obtained were subjected to Standard deviation and one way analysis of variance (ANOVA).

\section{Results and Discussion}

\section{Synthesis of silver nanoparticles from leaf extract of maize}

The reaction mixture which turned dark brown from yellow brownish color within 20 minutes is the indication of the synthesis of silver nanoparticles. The reduction silver nitrate to silver nitrite is confirmed by the dark brown color. The color change is due to Surface Plasmon Resonance (SPR) (Fig. 1)

\section{Scanning electron microscope (SEM) studies of silver nanoparticles:}

Silver nanoparticles synthesized from Zea mays L. were magnified using Scanning Electron Microscope that revealed that the nanoparticles are spherical in shape (Fig. 3). The image at 10, 00X and 20,000X revealed that the size of the nanoparticles was ranging between 500-1000 nm. The particles exhibited good uni- 
formity with further magnifications.

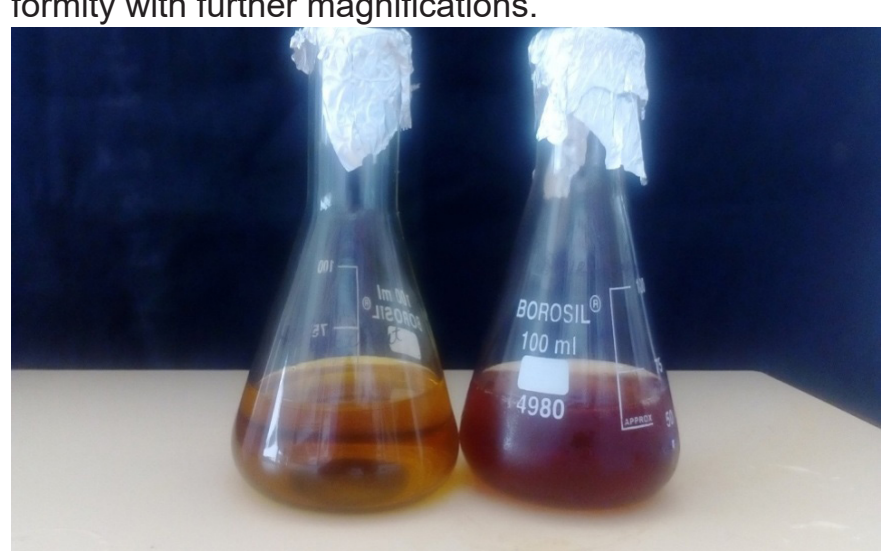

a)Control b) Silver nanoparticles

Fig. 1 Synthesis of silver nanoparticles from maize leaves

Characterization of synthesized silver nanoparticles:

UV-Visible spectra analysis of silver nanoparticles:

Silver nanoparticles showed maxiumum absorbance at $500 \mathrm{~nm}$ in various time intervals. (Fig. 2).The peak at $500 \mathrm{~nm}$ confirms the synthesis of nanoparticles which is due to Surface Plasmon Resonance.

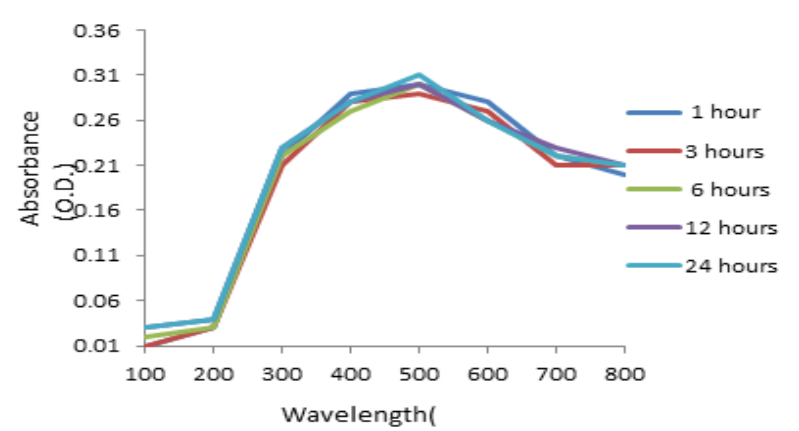

Fig. 2 UV-Vis absorption spectrum of silver nanoparticles from Zea mays L. leaf extract

Table 2 Parameters used for In vivo growth analysis of Zea mays $L$.

\begin{tabular}{|c|c|}
\hline S.No & Parameter used \\
\hline 1 & Root length \\
\hline 2 & Shoot length \\
\hline 3 & Leaf length \\
\hline 4 & Leaf surface area \\
\hline 5 & Fresh weight \\
\hline 6 & Dry weight \\
\hline
\end{tabular}

Energy dispersive X-ray spectrometer (EDAX) analysis of silver nanoparticles:

The synthesized silver nanoparticles showed a peak in the silver region of EDAX spectra confirmed the formation of silver nanoparticles (Fig. 4). EDAX reflects the purity of the silver nanoparticles which has negligible contamination of oxygen and chlorine.

Seed germination studies

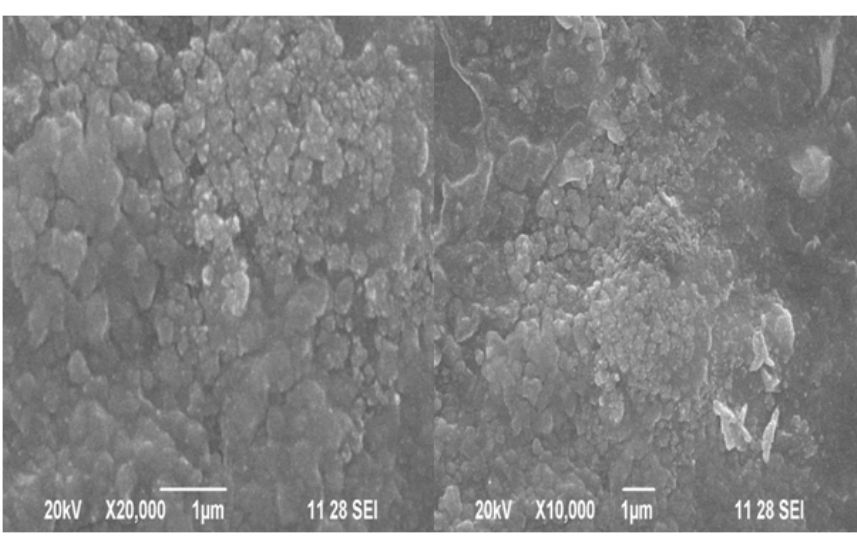

Fig. 3 Scanning Electron microscope of Silver nanoparticles.

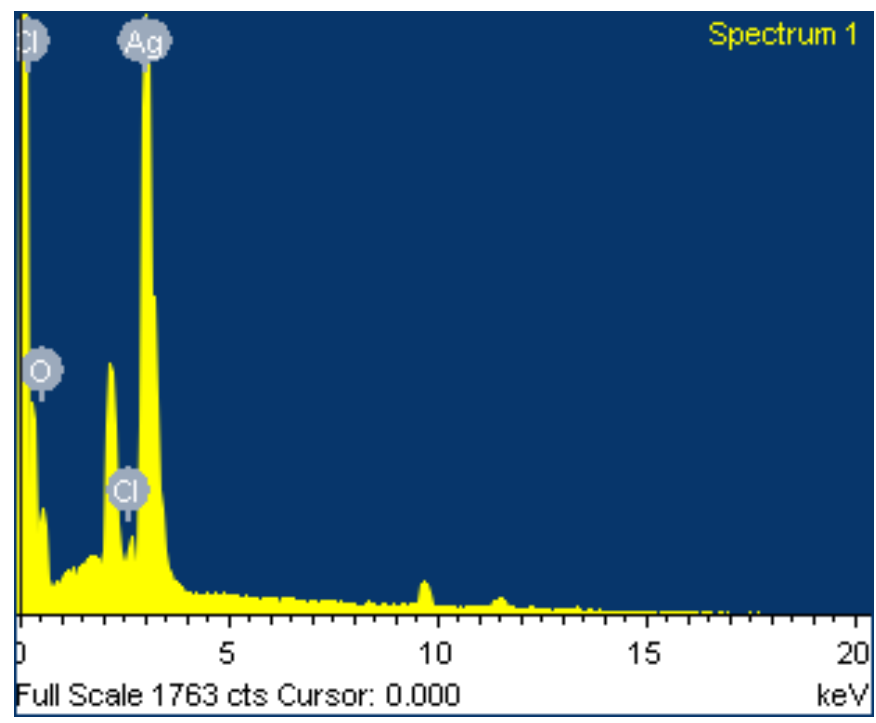

Fig. 4 Energy dispersive X-ray Spectrometry spectra of synthesized silver nanoparticle

Effect of silver nanoparticles on root and shoot length of Zea mays L. :

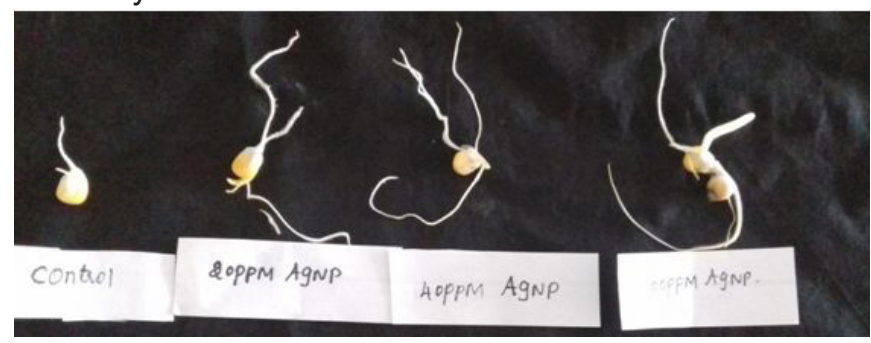

Figure 5 shows the seed germination studies of Zea mays L. supplemented with various concentration silver nanoparticles.

On $6^{\text {th }}$ day different concentrations $(20$ ppm, 40 ppm and 60 ppm) of silver nanoparticles supplemented to Zea mays L. showed maximum growth in root length with $60 \mathrm{ppm}(7.03 \pm 0.12 \mathrm{~cm})$ (Table 3$)$, followed by $40 \mathrm{ppm}$ $(4.43 \pm 0.12 \mathrm{~cm})$ and lower in $20 \mathrm{ppm}(3.67 \pm 0.15 \mathrm{~cm})$ and control $(2.00 \pm 0.10 \mathrm{~cm})$. The shoot length was higher in $60 \mathrm{ppm}(2.10 \pm 0.10 \mathrm{~cm})$ followed by $40 \mathrm{ppm}(1.07 \pm 0.12$ $\mathrm{cm})$ and lower in $20 \mathrm{ppm}(0.77 \pm 0.06 \mathrm{~cm})$ and control $(0.57 \pm 0.12 \mathrm{~cm})$. 
On $12^{\text {th }}$ day also the root length was found to be maximum with $60 \mathrm{ppm}(14.17 \pm 0.15 \mathrm{~cm})$ (Table 3), followed by 40 ppm $(8.67 \pm 0.25 \mathrm{~cm}), 20 \mathrm{ppm}(8.00 \pm 0.10$ $\mathrm{cm})$ and lower in control $(3.70 \pm 0.20 \mathrm{~cm})$. The shoot length was higher in $60 \mathrm{ppm}(4.53 \pm 0.25 \mathrm{~cm})$, followed by 40 ppm $(2.67 \pm 0.15 \mathrm{~cm})$ and lower in 20 ppm $(1.63 \pm 0.15$ $\mathrm{cm})$ and control $(1.47 \pm 0.15 \mathrm{~cm})$.

\section{Effect of silver nanoparticles on fresh and dry weight of Zea mays $L$. :}

Total fresh weight of Zea mays L. on $12^{\text {th }}$ day was higher in 60 ppm (2.33 \pm 0.06 grams)(Table 4), followed by 40 ppm ( $2.13 \pm 0.06$ grams $)$ and lower in 20 ppm(1.97 \pm 0.06 grams) and control (1.83 \pm 0.06 grams). Similarly the total dry weight of Zea mays L. was higher in 60 ppm (2.01 \pm 0.06 grams) followed by $40 \mathrm{ppm}(1.77 \pm 0.06$ grams), 20 ppm (1.53 \pm 0.06 grams) and lower in control $(1.27 \pm 0.06$ grams).

\section{In vivo growth of Zea maysL.supplemented with silver nanoparticles at one time.}

Figure. 6 shows the In vivo growth of Zea mays L. supplemented with silver nanoparticles at one time. After 15 days of growth the root length was higher in $60 \mathrm{ppm}$ $(12.17 \pm 0.21 \mathrm{~cm})$, followed by $40 \mathrm{ppm}(10.27 \pm 0.25 \mathrm{~cm})$ and lower in $20 \mathrm{ppm}(9.07 \pm 0.15 \mathrm{~cm})$ and control $(8.90 \pm$ $0.10 \mathrm{~cm})$. The shoot length was higher in $60 \mathrm{ppm}(16.37$ $\pm 0.15 \mathrm{~cm})$, followed by $40 \mathrm{ppm}(13.73 \pm 0.21 \mathrm{~cm}), 20$ ppm (11.23 $\pm 0.15 \mathrm{~cm})$ and lower in control (10.97 \pm 0.15 $\mathrm{cm})$.(Table 5).

Based on measuring the leaf length and leaf surface area of Zea mays L. it was revealed that the leaf length was higher in $60 \mathrm{ppm}(43.30 \pm 0.17 \mathrm{~cm})$, (Table 5) followed by 40 ppm $(39.50 \pm 0.10 \mathrm{~cm})$ and 20 ppm (37.77 $\pm 0.23 \mathrm{~cm})$. The leaf length was lower in control $(35.83$ $\pm 1.26 \mathrm{~cm}$ ). Similarly the leaf surface area was higher in $60 \mathrm{ppm}\left(39.23 \pm 0.21 \mathrm{~cm}^{2}\right)$, followed by $40 \mathrm{ppm}(35.07$ $\left.\pm 0.12 \mathrm{~cm}^{2}\right)$ and $20 \mathrm{ppm}\left(32.27 \pm 0.25 \mathrm{~cm}^{2}\right)$. The leaf surface area of control was $28.80 \pm 0.26 \mathrm{~cm}^{2}$.

The leaf weight of Zea mays L. was higher in 60 ppm (0.899 \pm 0.003 grams), followed by 40 ppm (0.799 \pm 0.002 grams $)$ and 20 ppm (0.699 \pm 0.004 grams $)$. The leaf weight of the control was $0.666 \pm 0.008$ grams. The whole plant weight of Zea mays L. was also higher in 60 ppm (2.268 \pm 0.015 grams), followed by 40 ppm (2.131 \pm 0.014 grams $)$ and 20 ppm (1.907 \pm 0.010 grams $)$. The whole plant weight of the control was $1.810 \pm 0.009$ grams.(Table 6).

\section{In vivo growth analysis of Zea maysL.supplemented with silver nanoparticles continuously for 15 days.}

Figure. 7 shows the Invivo growth of Zea mays L. supplemented with various concentrations (20 ppm, 40 ppm and $60 \mathrm{ppm}$ ) of silver nanoparticles continuously for 15 days. The root length of Zea mays $L$. was higher in $60 \mathrm{ppm}(12.17 \pm 0.21 \mathrm{~cm})$, followed by $40 \mathrm{ppm}$ (10.27 \pm $0.25 \mathrm{~cm})$ and $20 \mathrm{ppm}(9.07 \pm 0.15 \mathrm{~cm})$. The root length

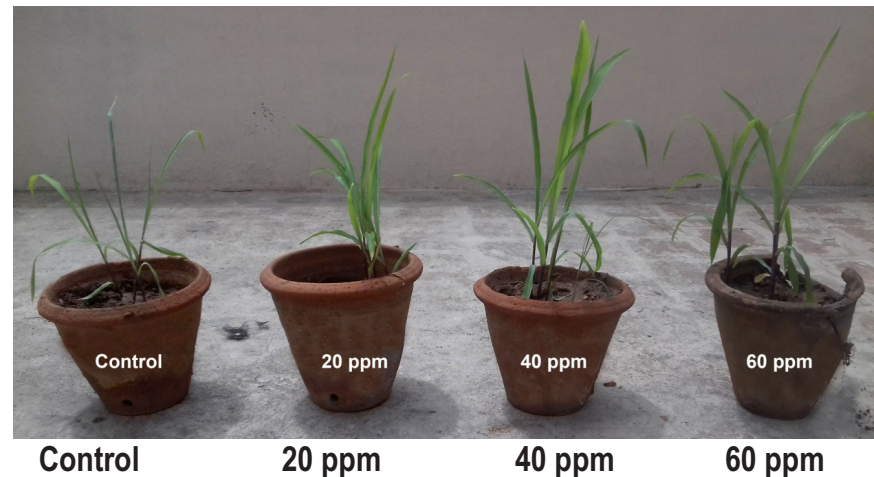

Fig. 6 In vivo growth of Zea maysL.supplemented with silver nanoparticles at one time

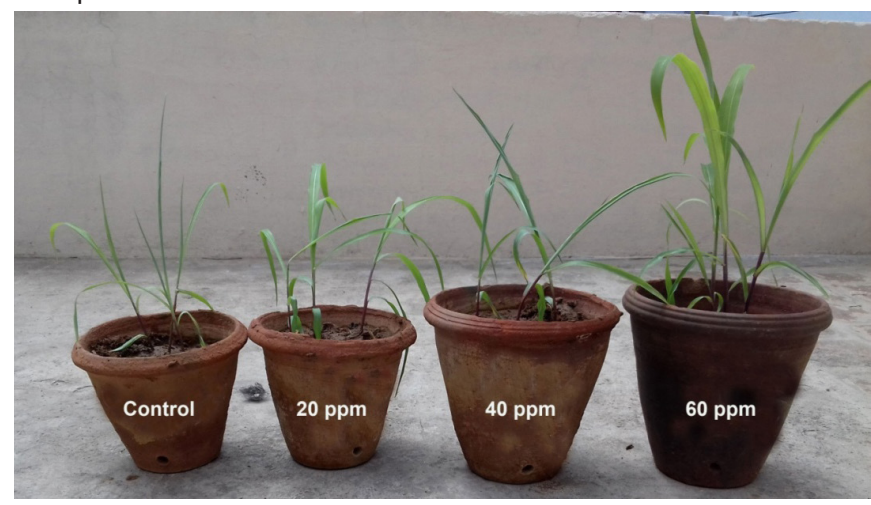

Fig. 7 In vivo growth analysis of Zea maysL.supplemented with silver nanoparticles continuously for 15 days

Table 3 Effect of silver nanoparticles on root and shoot length of Zea mays $L$. seeds (6thand 12thday)

\begin{tabular}{|c|c|c|c|c|}
\hline \multirow{2}{*}{$\begin{array}{c}\text { Concentration } \\
\text { of silver } \\
\text { nanoparticles }\end{array}$} & \multicolumn{2}{|c|}{ 6th day } & \multicolumn{2}{c|}{ 12th day } \\
\cline { 2 - 5 } & $\begin{array}{c}\text { Root } \\
\text { length }(\mathrm{cm})\end{array}$ & $\begin{array}{c}\text { Shoot } \\
\text { length }(\mathrm{cm})\end{array}$ & $\begin{array}{c}\text { Root } \\
\text { length}(\mathrm{cm})\end{array}$ & $\begin{array}{c}\text { Shoot } \\
\text { length }(\mathrm{cm})\end{array}$ \\
\hline Control & $2.00 \pm 0.10$ & $0.57 \pm 0.08$ & $3.70 \pm 0.20$ & $1.47 \pm 0.15$ \\
\hline $20 \mathrm{ppm}$ & $3.67 \pm 0.15$ & $0.77 \pm 0.06$ & $8.00 \pm 0.10$ & $1.63 \pm 0.15$ \\
\hline $40 \mathrm{ppm}$ & $4.43 \pm 0.12$ & $1.07 \pm 0.12$ & $8.67 \pm 0.25$ & $2.67 \pm 0.15$ \\
\hline $60 \mathrm{ppm}$ & $7.03 \pm 0.12$ & $2.10 \pm 0.10$ & $14.47 \pm 0.15$ & $4.53 \pm 0.25$ \\
\hline
\end{tabular}

Values represent the mean $( \pm$ ) standard error of three independent experiments. All the experiments were statistically analyzed by One way Anova using SPSS interpretation. The results were significant at $p<.05$

Table 4 Effect of silver nanoparticles on fresh and dry weight of Zea mays L. seeds on 12th day

\begin{tabular}{|c|c|c|}
\hline $\begin{array}{c}\text { Concentration } \\
\text { of silver } \\
\text { nanoparticles } \\
\text { (ppm) }\end{array}$ & $\begin{array}{c}\text { Fresh weight } \\
\text { of Zea mays } \\
\text { L.(grams) }\end{array}$ & $\begin{array}{c}\text { Dry weight of Zea } \\
\text { mays L. (grams) }\end{array}$ \\
\hline Control & $1.83 \pm 0.06$ & $1.27 \pm 0.06$ \\
\hline 20 & $1.97 \pm 0.06$ & $1.53 \pm 0.06$ \\
\hline 40 & $2.13 \pm 0.06$ & $1.77 \pm 0.06$ \\
\hline 60 & $2.33 \pm 0.06$ & $2.01 \pm 0.06$ \\
\hline
\end{tabular}

Values represent the mean $( \pm)$ standard error of three independent experiments. All the experiments were statistically analyzed by One way Anova using SPSS interpretation. The results were significant at $p<.05$ 
Table 5 Root and shoot length of Zea mays L. supplemented with silver nanoparticles at one time.

\begin{tabular}{|c|c|c|c|c|}
\hline $\begin{array}{c}\text { Concentration of } \\
\text { silver nanoparticles } \\
(\mathrm{ppm})\end{array}$ & Root length $(\mathrm{cm})$ & Shoot length $(\mathrm{cm})$ & Leaf length $(\mathrm{cm})$ & $\begin{array}{c}\text { Leaf surface } \\
\text { area }(\mathrm{cm} 2)\end{array}$ \\
\hline Control & $8.90 \pm 0.10$ & $10.97 \pm 0.15$ & $35.83 \pm 1.26$ & $28.80 \pm 0.26$ \\
\hline 20 & $9.07 \pm 0.15$ & $11.23 \pm 0.15$ & $37.77 \pm 0.23$ & $32.27 \pm 0.25$ \\
\hline 40 & $10.27 \pm 0.25$ & $13.73 \pm 0.21$ & $39.50 \pm 0.10$ & $35.07 \pm 0.12$ \\
\hline 60 & $12.17 \pm 0.21$ & $16.37 \pm 0.15$ & $43.30 \pm 0.17$ & $39.23 \pm 0.21$ \\
\hline
\end{tabular}

Values represent the mean ( \pm ) standard error of three independent experiments. All the experiments were statistically analyzed by One way Anova using SPSS interpretation. The results were significant at $p<.05$ Table 6 Root, shoot, leaf and whole plant weight of Zea mays L. supplemented with silver nanoparticles at one time.

\begin{tabular}{|c|c|c|c|c|}
\hline $\begin{array}{c}\text { Concentration of silver } \\
\text { nanoparticles }(\mathrm{ppm})\end{array}$ & $\begin{array}{c}\text { Root } \\
\text { weight(grams) }\end{array}$ & $\begin{array}{c}\text { Shoot } \\
\text { weight(grams) }\end{array}$ & $\begin{array}{c}\text { Leaf } \\
\text { weight(grams) }\end{array}$ & $\begin{array}{c}\text { Whole plant } \\
\text { weight(grams) }\end{array}$ \\
\hline Control & $0.545 \pm 0.003$ & $0.612 \pm 0.003$ & $0.666 \pm 0.008$ & $1.810 \pm 0.009$ \\
\hline 20 & $0.554 \pm 0.003$ & $0.661 \pm 0.003$ & $0.699 \pm 0.004$ & $1.907 \pm 0.010$ \\
\hline 40 & $0.596 \pm 0.002$ & $0.754 \pm 0.003$ & $0.799 \pm 0.002$ & $2.131 \pm 0.014$ \\
\hline 60 & $0.621 \pm 0.002$ & $0.766 \pm 0.004$ & $0.899 \pm 0.003$ & $2.268 \pm 0.015$ \\
\hline
\end{tabular}

Values represent the mean ( \pm ) standard error of three independent experiments. All the experiments were statistically analyzed by One way Anova using SPSS interpretation. The results were significant at $p<.05$

Table 7 Root and shoot length of Zea mays L. supplemented with silver nanoparticle continuosly for 15 days.

\begin{tabular}{|c|c|c|c|c|}
\hline $\begin{array}{c}\text { Concentration of silver } \\
\text { nanoparticles }(\mathbf{p p m})\end{array}$ & $\begin{array}{c}\text { Root } \\
\text { length(cm) }\end{array}$ & $\begin{array}{c}\text { Shoot } \\
\text { length(cm) }\end{array}$ & $\begin{array}{c}\text { Leaf } \\
\text { length(cm) }\end{array}$ & Leaf surface area(cm2) \\
\hline Control & $8.90 \pm 0.10$ & $10.97 \pm 0.15$ & $35.83 \pm 1.26$ & $28.80 \pm 0.26$ \\
\hline 20 & $9.07 \pm 0.15$ & $11.23 \pm 0.15$ & $37.23 \pm 067$ & $34.80 \pm 0.10$ \\
\hline 40 & $10.27 \pm 0.25$ & $13.73 \pm 0.21$ & $39.57 \pm 0.40$ & $38.13 \pm 0.15$ \\
\hline 60 & $12.17 \pm 0.21$ & $16.37 \pm 0.15$ & $45.13 \pm 0.15$ & $40.17 \pm 0.15$ \\
\hline
\end{tabular}

Values represent the mean ( \pm ) standard error of three independent experiments. All the experiments were statistically analyzed by One way Anova using SPSS interpretation. The results were significant at $p<.05$ Table 8 Root, shoot, leaf and whole plant weight of Zea mays L. supplemented with silver nanoparticles continuosly for 15 days.

\begin{tabular}{|c|c|c|c|c|}
\hline $\begin{array}{c}\text { Concentration of } \\
\text { silver nanoparticles } \\
(\mathrm{ppm})\end{array}$ & $\begin{array}{c}\text { Root } \\
\text { weight(grams) }\end{array}$ & $\begin{array}{c}\text { Shoot } \\
\text { weight(grams) }\end{array}$ & Leaf weight(grams) & $\begin{array}{c}\text { Whole plant } \\
\text { weight(grams) }\end{array}$ \\
\hline Control & $0.545 \pm 0.003$ & $0.612 \pm 0.003$ & $0.666 \pm 0.008$ & $1.810 \pm 0.009$ \\
\hline 20 & $0.559 \pm 0.003$ & $0.664 \pm 0.002$ & $0.693 \pm 0.006$ & $1.914 \pm 0.004$ \\
\hline 40 & $0.602 \pm 0.003$ & $0.798 \pm 0.001$ & $0.808 \pm 0.001$ & $2.203 \pm 0.005$ \\
\hline 60 & $0.638 \pm 0.002$ & $0.805 \pm 0.004$ & $0.910 \pm 0.002$ & $2.353 \pm 0.006$ \\
\hline
\end{tabular}

Values represent the mean ( \pm ) standard error of three independent experiments. All the experiments were statistically analyzed by One way Anova using SPSS interpretation. The results were significant at $\mathrm{p}<.05$

of control was $8.90 \pm 0.10 \mathrm{~cm}$. Similarly the shoot length was also higher in $60 \mathrm{ppm}(16.37 \pm 0.15 \mathrm{~cm})$, followed by $40 \mathrm{ppm}(13.73 \pm 0.21 \mathrm{~cm})$ and $20 \mathrm{ppm}(11.23 \pm 0.15$ $\mathrm{cm})$. The shoot length of the control was $10.97 \pm 0.15$ cm. (Table 7).

Based on measuring the leaf length and leaf surface area of Zea mays $L$. it was revealed that the leaf length was higher in $60 \mathrm{ppm}(45.13 \pm 0.15 \mathrm{~cm})$, (Table $7)$, followed by $40 \mathrm{ppm}(39.57 \pm 0.40 \mathrm{~cm})$ and $20 \mathrm{ppm}$ $(37.23 \pm 067 \mathrm{~cm})$. The leaf length was lower in control $(35.83 \pm 1.26 \mathrm{~cm})$. Similarly the leaf surface area was higher in $60 \mathrm{ppm}\left(40.17 \pm 0.15 \mathrm{~cm}^{2}\right)$, followed by $40 \mathrm{ppm}$ $\left(38.13 \pm 0.15 \mathrm{~cm}^{2}\right)$ and $20 \mathrm{ppm}\left(34.80 \pm 0.10 \mathrm{~cm}^{2}\right)$. The leaf surface area of control was $28.80 \pm 0.26 \mathrm{~cm}^{2}$. 


\section{Biomass analyses of Zea mays $L$. supplemented with silver nanoparticles continuously for 15 days.}

The root weight of Zea mays L. was higher in 60 ppm $(0.638 \pm 0.002$ grams), (Table 8$)$, followed by 40 ppm (0.602 \pm 0.003 grams) and 20 ppm (0.559 \pm 0.003 grams). The root weight of the control was $0.545 \pm 0.003$ grams. Similarly the shoot weight of Zea mays L. was also higher in $60 \mathrm{ppm}$ (0.805 \pm 0.004 grams), followed by 40 ppm (0.798 \pm 0.001 grams) and 20 ppm (0.664 \pm 0.002 grams). The shoot weight of the control was 0.612 \pm 0.003 grams.

The leaf weight of Zea mays L. was higher in 60 ppm $(0.910 \pm 0.002$ grams), (Table 8$)$, followed by 40 ppm (0.808 \pm 0.001 grams) and 20 ppm (0.693 \pm 0.006 grams). The leaf weight of the control was $0.666 \pm 0.008$ grams. The whole plant weight of Zea mays $\mathrm{L}$. was also higher in 60 ppm (2.353 \pm 0.006 grams), followed by 40 ppm (2.203 \pm 0.005 grams) and 20 ppm (1.914 \pm 0.004 grams). The whole plant weight of the control was 1.810 \pm 0.009 grams.

\section{Estimation of Protein:}

The protein content of Zea mays L. increased with increasing concentration (60 ppm) of silver nanoparticles. Silver nanoparticles supplemented at one time and continuosly for 15 days to Zea mays L. showed higher protein content with 60 ppm (Fig. 8) when compared to control.

\section{Estimation of Aminoacids:}

The aminoacids content of Zea mays L. decreased significantly with increasing concentration of silver nanoaparticles (Fig. 9). The aminoacid content of control was $5.15 \mathrm{mg}$.

\section{Estimation of Proline:}

Proline accumulates in Zea mays L. in response to environmental stress. The proline accumulation increased with increasing concentration of silver nanoparticles from 20 ppm to 60 ppm (Fig. 10).

\section{Analysis of chlorophyll:}

Silver nanoparticle supplemented at one time on day 1 in Zea mays L. possess increase in the chlorophyll content from control (Total Chlorophyll $17.6 \mathrm{mg}$ ) to 60 ppm (Total Chlorophyll $25.3 \mathrm{mg}$ ) concentration of silver nanoparticles. The chlorophyll content of $20 \mathrm{ppm}$ and $40 \mathrm{ppm}$ concentrations were $18.0 \mathrm{mg}$ and 22.3 mg respectively. Silver nanoparticles supplemented continuously for 15 days in Zea mays L. possess increase in the chlorophyll content from control to 20 ppm ( Total Chlorophyll $19.8 \mathrm{mg}$ ). Further increase in the concentration of silver nanoparticles 40 ppm (16.1 mg) and 60 ppm (15.0 mg) decreases the chlorophyll content.

\section{Analysis of silver nanoparticles in plant material:}

The results of the atomic absorption spectrometry reveals that among the various concentration (20 ppm, 40 ppm and $60 \mathrm{ppm}$ ) of silver nanoparticles supplemented to Zea mays L. at one time, 60 ppm ( $0.0842 \pm 0.007$ ppm) has more silver particles followed by 40ppm (0.0094 \pm 0.0004$)$ and 20 ppm (0.0064 \pm 0.0004$)$. The silver nanoparticle in control was $0.002 \pm 0.0033$.

Similarly among the various concentration (20 ppm, 40 ppm and 60 ppm) of silver nanoparticles supplemented to Zea mays L. continuously for 15 days, $60 \mathrm{ppm}(0.1147 \pm 0.0045)$ has more silver particles followed by 40 ppm $(0.1085 \pm 0.007$ ppm) and 20 ppm $(0.0721 \pm 0.0015)$ The silver nanoparticles in control was $0.002 \pm 0.0033$

\section{Accumulation Factor (AF)}

To evaluate the silver nanoparticle accumulation in the plant tissue, the accumulation factor (AF) was calculated on the effect of silver on Zea mays L. and tabulated in Table 9.

The accumulation factor was significantly increased with the increasing concentrations of silver nanoparticles.

Accordingly, the accumulation factor in Zea mays $L$. was ranging from $0.12 \mathrm{ppm}$ to $1.68 \mathrm{ppm}$ with silver nanoparticles supplemented at one time. Similarly the accumulation factor in Zea mays $\mathrm{L}$. was ranging from $2.17 \mathrm{ppm}$ to $2.29 \mathrm{ppm}$ with silver nanoparticles supplemented continuously for 15 days.

\section{Discussion:}

The present study correlates with a study by Table 9 Accumulation factor of silver nanoparticle

\begin{tabular}{|c|c|c|c|c|}
\hline Nanoparticles & $\begin{array}{c}\text { Control } \\
(\mathrm{ppm})\end{array}$ & $20 \mathrm{ppm}$ & $\begin{array}{c}40 \\
\mathrm{ppm}\end{array}$ & $60 \mathrm{ppm}$ \\
\hline $\begin{array}{c}\text { Silver nanoparticles } \\
\text { supplemented at one } \\
\text { time to Zea mays L. }\end{array}$ & 0.04 & 0.12 & 0.18 & 1.68 \\
\hline $\begin{array}{c}\text { Silver nanoparticles } \\
\text { supplemented } \\
\text { continuosly for 15 days } \\
\text { to Zea mays L. }\end{array}$ & 0.04 & 2.17 & 2.17 & 2.29 \\
\hline
\end{tabular}

Dong Van et.al., who evaluated copper nanoparticles in maize development and growth. He proved that copper nanoparticles enhances chlorophyll, carotenoid content plant growth, biomass under drought. He inferred that copper nanoparticles can be a suitable fertilizer in agricultural applications of maize and its productivity (11). In our study chlorophyll content increases with 60 ppm concentration of nanoparticles supplemented on day 1. However chlorophyll decreased with 40 and 60 ppm concentrations of silver nanoparticles supplemented for 15 days continuously.

$\mathrm{Ag}$ and $\mathrm{Au}$ nanoparticles on the early growth and germination of radish and alfalfa were determined. 


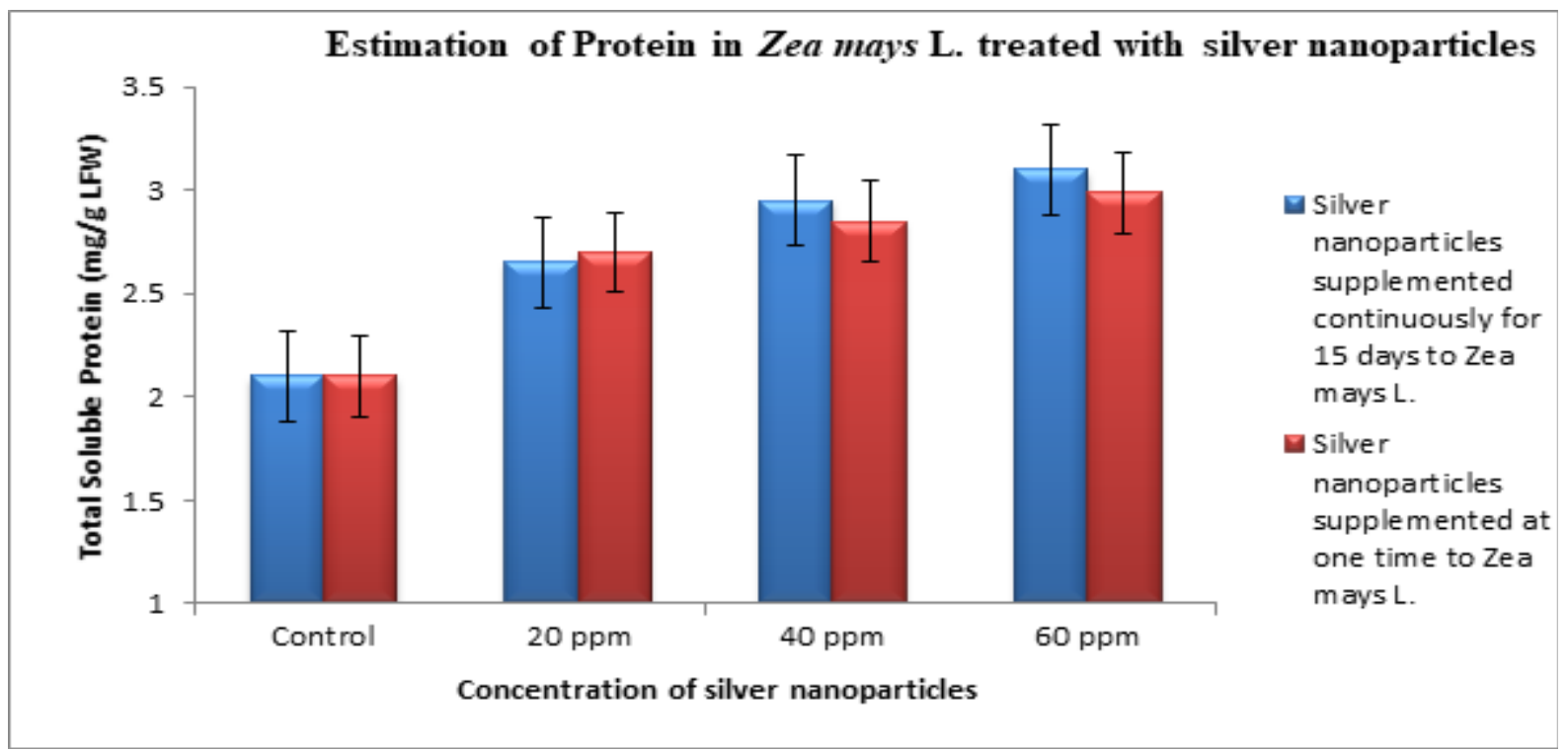

Fig. 8 Estimation of protein in Zea mays L. supplemented with silver nanoparticles. Values represent the mean ( \pm ) standard error of three independent experiments

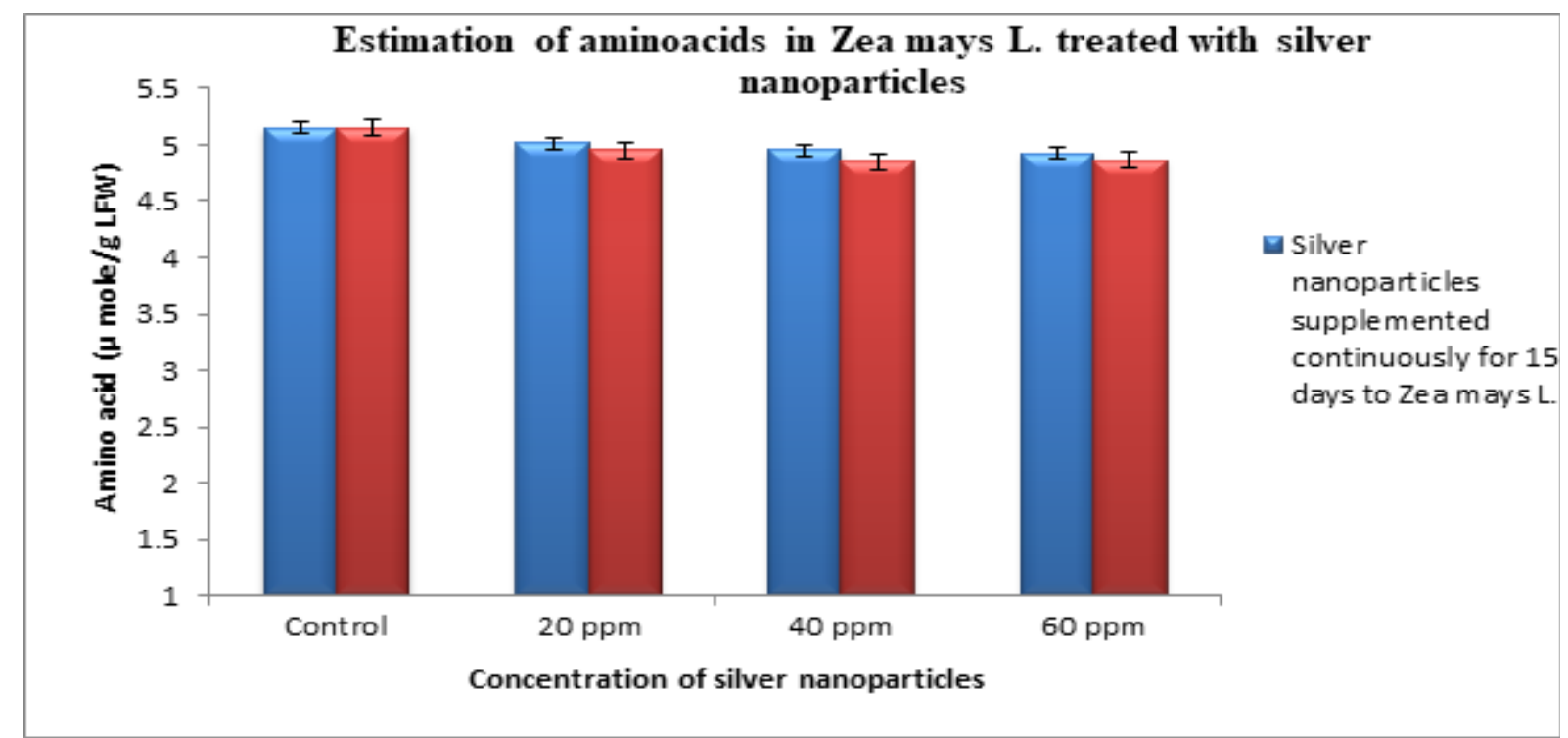

Fig. 9 Estimation of aminoacid in Zea mays L. supplemented with silver nanoparticles. Values represent the mean $( \pm)$ standard error of three independent experiments.

Both nanoparticles increased the shoot, root length of radish while in alfalfa the nanoparticles inhibited the growh of root and shoot. The intake of Ag nanoparticle is more dependent on its dose (12). Low dosage of silver nanoparticle is cost efficient treatment on seed that can be used for agricultural applications and also in improving the economic status of farmers. Considering the dosage of silver nanoparticles in the present study $60 \mathrm{ppm}$ of silver nanoparticles was taken as the maximum dosage, as further increase would affect the growth of the plant.

Nano induced seed treatment avoid release of huge amount of nanomaterials in field with lowering impacts to the environment. Therefore nanoparticles applied on plants induce investigations to get a clear understanding plant surface-nanoparticle interactions and uptake of them inside the plant system (6).

\section{Conclusion}

Our study reveals that silver nanoparticles have potential to enhance the growth of Zea mays L. Among the various concentrations (20 ppm, $40 \mathrm{ppm}$ and $60 \mathrm{ppm}$ ) of copper nanoparticles, $60 \mathrm{ppm}$ is considered as the optimum level for the growth of Zea mays L. However increasing concentrations of silver nanoparticles would affect the plant growth and soil. The results of this study would provoke further research in agricultural nanotechnology with mixed effects of nanoparticles in the development and growth of plants.

\section{References:}

1. Hafizi, Z., \& Nasr, N. (2018). The effect of zinc oxide nanoparticles on safflower plant growth and physiology. Engineering, Technology \& Applied 


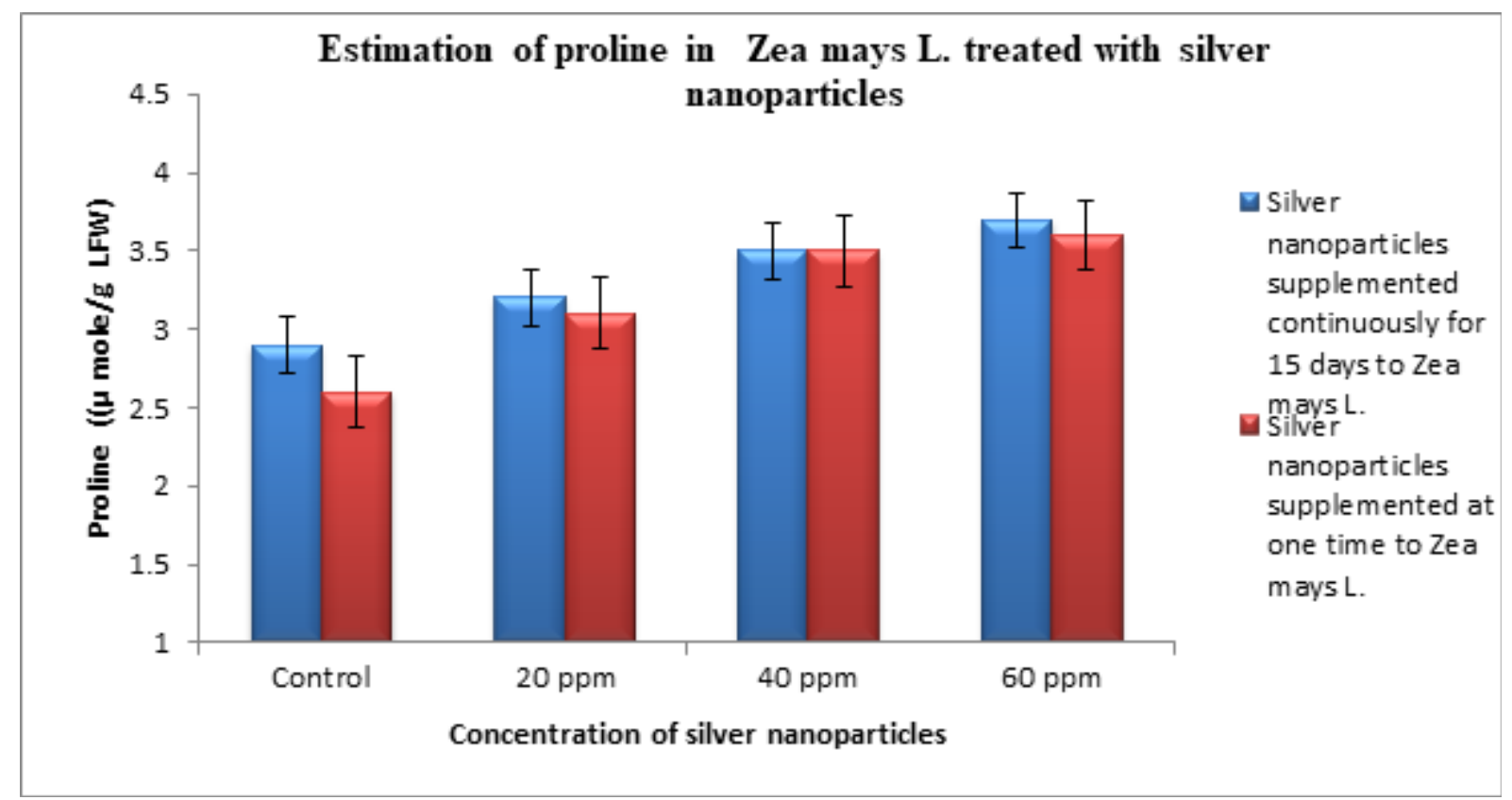

Fig. 10 Estimation of proline in Zea mays L. supplemented with silver nanoparticles. Values represent the mean $( \pm)$ standard error of three independent experiments.

Science Research, 8(1), 2508-2513.

2. Zuverza-Mena, N., Armendariz, R., Peralta-Videa, J. R., \& Gardea-Torresdey, J. L. (2016). Effects of silver nanoparticles on radish sprouts: root growth reduction and modifications in the nutritional value. Frontiers in plant science, 7, 90.

3. Aritonang, H. F., Koleangan, H., \& Wuntu, A. D. (2019). Synthesis of silver nanoparticles using aqueous extract of medicinal plants'(Impatiens balsamina and Lantana camara) fresh leaves and analysis of antimicrobial activity. International journal of microbiology, 2019.

4. Hemlata, Meena, P. R., Singh, A. P., \& Tejavath, K. K. (2020). Biosynthesis of silver nanoparticles using cucumis prophetarum aqueous leaf extract and their antibacterial and antiproliferative activity against cancer cell lines. ACS omega, 5(10), 5520-5528.

5. Castillo-Henríquez, L., Alfaro-Aguilar, K., UgaldeÁlvarez, J., Vega-Fernández, L., Montes de OcaVásquez, G., \& Vega-Baudrit, J. R. (2020). Green Synthesis of Gold and Silver Nanoparticles from Plant Extracts and Their Possible Applications as Antimicrobial Agents in the Agricultural Area. Nanomaterials, 10(9), 1763.

6. Goswami, P., \& Mathur, J. (2019). Positive and negative effects of nanoparticles on plants and their applications in agriculture. Plant Science Today, 6(2), 232-242.

7. Acharya, P., Jayaprakasha, G. K., Crosby, K. M., Jifon, J. L., \& Patil, B. S. (2020). Nanoparticlemediated seed priming improves germination, growth, yield, and quality of watermelons (Citrullus lanatus) at multi-locations in Texas. Scientific reports, 10(1), 1-16.

8. Prażak, R., Święciło, A., Krzepiłko, A., Michałek, S., \& Arczewska, M. (2020). Impact of Ag Nanoparticles on Seed Germination and Seedling Growth of Green Beans in Normal and Chill Temperatures. Agriculture, 10(8), 312.

9. Sadak, M. S. (2019). Impact of silver nanoparticles on plant growth, some biochemical aspects, and yield of fenugreek plant (Trigonella foenumgraecum). Bulletin of the National Research Centre, 43(1), 1-6.

10. Gohari, G., Mohammadi, A., Akbari, A., Panahirad, S., Dadpour, M. R., Fotopoulos, V., \& Kimura, S. (2020). Titanium dioxide nanoparticles (TiO 2 NPs) promote growth and ameliorate salinity stress effects on essential oil profile and biochemical attributes of Dracocephalum moldavica. Scientific reports, 10(1), 1-14.

11. Van Nguyen, D., Nguyen, H. M., Le, N. T., Nguyen, K. H., Nguyen, H. T., Le, H. M., \& Van Ha, C. (2021). Copper nanoparticle application enhances plant growth and grain yield in maize under drought stress conditions. Journal of Plant Growth Regulation, 1-12.

12. Kim, M. J., Kim, W., \& Chung, H. (2020). Effects of silver-graphene oxide on seed germination and early growth of crop species. PeerJ, 8, e8387. 